\title{
Intradermal skin tests for rocuronium and cisatracurium in patients with a history of allergy: a retrospective study
}

\author{
Yu Yil Kim, Ik Thae Kim, Sung In Shin, and So Mang Yim \\ Department of Anesthesiology and Pain Medicine, Presbyterian Medical Center, Jeonju, Korea
}

Background: Neuromuscular blocking agents (NMBAs) are a leading cause of perioperative anaphylaxis. However, the performance of systematic screening skin tests to detect reactions for NMBAs prior to general anesthesia is not recommended. We retrospectively examined intradermal tests (IDTs) for rocuronium and cisatracurium in patients with a history of allergy.

Methods: We reviewed the records of patients who underwent IDTs for NMBAs between January 1 and December 31, 2016. We analyzed the patients' allergy histories and skin test results for NMBAs.

Results: The overall prevalence of positive IDTs was 5.8\% (26/451), and there was no significant difference in prevalence among allergy types $(\mathrm{P}=0.655)$. In logistic regression analysis, there was no allergy history that had a significant effect on positive IDT for NMBAs.

Conclusions: We found no association between allergy history and positive skin test for NMBAs. Therefore, a systematic screening test for NMBAs or other anesthetic agents before anesthesia is not considered necessary even in patients with an allergy history.

Keywords: Intradermal test; Neuromuscular blocking agents; Perioperative anaphylaxis.

\section{Introduction}

Perioperative anaphylaxis is a rare phenomenon, but it is a very serious allergic reaction that can lead to life-threatening consequences despite proper treatment. Many drugs or sub-

Corresponding author: Yu Yil Kim, M.D.

Department of Anesthesiology and Pain Medicine, Presbyterian Medical Center, 365, Seowon-ro, Wansan-gu, Jeonju 54987, Korea

Tel: 82-63-230-1594, Fax: 82-63-230-1599

Email: gangoaogi@naver.com

ORCID: https://orcid.org/0000-0003-3455-9251

Received: June 27, 2017.

Revised: July 27, 2017 (1st); August 14, 2017 (2nd).

Accepted: August 15, 2017.

Korean J Anesthesiol 2018 August 71(4): 296-299

https://doi.org/10.4097/kja.d.18.27156 stances used in the perioperative period, such as neuromuscular blocking agents (NMBAs), latex, antibiotics, hypnotics, and antiseptic agents, may be causative agents of anaphylaxis. Among these agents, antibiotics and NMBAs, one of the anesthetics, are known to most commonly elicit anaphylaxis [1-3]. To prevent anaphylaxis under subsequent occasions upon which anesthesia is performed, it is necessary to identify the causative agents in patients who experience allergic reactions, including anaphylaxis, during anesthesia. However, because anaphylaxis due to anesthetics including NMBAs is very rare, and evidence is lacking to support the predictive value of skin tests, performance of systematic screening skin tests to identify reactions to anesthetic agents prior to anesthesia to prevent anaphylaxis is not recommended in the general population [4].

Nevertheless, numerous studies have been performed to identify risk factors capable of predicting anesthetic-related allergies. Some studies have reported that a history of drug allergy

(c) This is an open-access article distributed under the terms of the Creative Commons Attribution Non-Commercial License (http://creativecommons.org/ licenses/by-nc/4.0/), which permits unrestricted non-commercial use, distribution, and reproduction in any medium, provided the original work is properly cited. 
is a predictive factor of positive skin tests for NMBAs, and have emphasized the necessity of screening tests for NMBAs prior to anesthesia in patients with a history of drug allergic reactions [5-7].

In the present study, we conducted a retrospective analysis of the relationship between intradermal tests (IDTs) for NMBAs and allergy history in patients who underwent IDTs for anesthetic agents between January 1 and December 31 of 2016.

\section{Materials and Methods}

This study was conducted after approval by the committee of the Institutional Review Board of our hospital.

Study participants included 480 patients who underwent the skin tests to anesthetic drugs prior to anesthesia owing to their histories of allergies between January 1 and December 31 of 2016. Patients who were taking antihistamines or long-term steroids were excluded.

Subjects' allergy histories and results of skin tests for NMBAs were retrospectively investigated through medical records. Allergies were classified as food, drug, atopy, and others (metal, insect, etc.). Asthma, allergic rhinitis, and atopic dermatitis were included under atopy. Drug allergies were subclassified into antibiotic or other drug allergy.

Skin tests for NMBAs were performed as follows: Surgeons or anesthesiologists requested the skin tests for anesthetic drugs prior to anesthesia after confirming the allergic histories of patients (atopy, food, drug and other allergies). IDTs were performed in the allergy unit of our hospital. The NMBAs used in the IDT were rocuronium (Esmeron ${ }^{\circledR}$, Organon, The Netherlands) and cisatracurium (Nimbex ${ }^{\circledR}$, GlaxoSmithKline, UK),

Table 1. Concentrations of NMBAs Used for Intradermal Tests

\begin{tabular}{lccc}
\hline \multicolumn{1}{c}{ NMBA } & $\begin{array}{c}\text { Undiluted } \\
\text { drug }(\mathrm{mg} / \mathrm{ml})\end{array}$ & Dilution & $\begin{array}{c}\text { Concentration } \\
(\mu \mathrm{g} / \mathrm{ml})\end{array}$ \\
\hline Rocuronium & 10 & $1: 100$ & 100 \\
Cisatracurium & 2 & $1: 100$ & 20 \\
\hline
\end{tabular}

NMBAs: neuromuscular blocking agents. which were commercially available. Rocuronum was used as a $10 \mathrm{mg} / \mathrm{ml}$ solution, and cisatracurium was used as a solution of $2 \mathrm{mg} / \mathrm{ml}$. Each drug was diluted to 1 : 100 with $0.9 \%$ saline, which is a maximum concentration that was normally non-reactive. Histamine solution was used as a positive control, and $0.9 \%$ saline as a negative control (Table 1). A volume of $0.02 \mathrm{ml}$ of prepared drugs were injected to produce wheals that were less than $4 \mathrm{~mm}$ in diameter on the anterior part of the forearm of the patient. Fifteen minutes after the intradermal injection, the two largest diameters of the wheal that were perpendicular to each other were measured and averaged. The IDT was considered positive when the wheal diameter was $8 \mathrm{~mm}$ or more [8].

Data are expressed as number (\%). Statistical analysis was conducted using SPSS (SPSS Inc., USA), and the chi-square test was used to compare the results of IDT. In addition, logistic regression analysis was performed to evaluate the correlation between each allergy and positive IDTs for NMBAs. A value of $\mathrm{P}<0.05$ was considered statistically significant.

\section{Results}

In this study, retrospective analysis of 480 patients was conducted. Data for 29 patients with unreliable skin test results were excluded because anti-histamine agents or steroid medications were used in the performance of the skin test. Among the included patients, there were 104 (23.0\%) with food allergy; 143 (31.7\%) with drug allergy; 43 (9.5\%) with antibiotic allergy; and 27 (6.0\%) with atopy. Only 26 out of 451 patients (5.8\%) showed positive IDTs for NMBAs. Among patients with food allergy, drug allergy, or atopy, there were no significant differences in the incidence of positive IDT $(\mathrm{P}=0.655)$. Furthermore, logistic regression analysis conducted to investigate the correlation between allergy and IDT for NMBAs revealed no significant relationship for any allergy histories (Table 2). In addition, there were no patients with allergic reactions during anesthesia.

\section{Discussion}

Perioperative anaphylaxis is an immediate immune-mediated

Table 2. Results of Intradermal Skin Tests to NMBAs and Logistic Regression Analysis

\begin{tabular}{|c|c|c|c|c|c|}
\hline & Rocuronium & Cisatracurium & Both NMBAs & Total & $P$ value \\
\hline Food $(n=104)$ & $0(0.0)$ & $8(7.6)$ & $0(0.0)$ & $8(7.6)$ & 0.194 \\
\hline $\operatorname{Drug}(\mathrm{n}=143)$ & $0(0.0)$ & $7(4.8)$ & $0(0.0)$ & $7(4.8)$ & 0.457 \\
\hline Antibiotic $(n=43)$ & $0(0.0)$ & $2(4.6)$ & $0(0.0)$ & & 0.932 \\
\hline Other $(\mathrm{n}=100)$ & $0(0.0)$ & $5(5.0)$ & $0(0.0)$ & & \\
\hline Atopy $(\mathrm{n}=27)$ & $1(3.7)$ & $1(3.7)$ & $0(0.0)$ & $2(7.4)$ & 0.380 \\
\hline Others $(\mathrm{n}=194)$ & $3(1.5)$ & $10(5.1)$ & $2(1.0)$ & $11(5.6)$ & 0.323 \\
\hline Total $(\mathrm{n}=451)$ & $4(0.9)$ & $24(5.3)$ & $2(0.4)$ & $26(5.8)$ & \\
\hline
\end{tabular}

Data are expressed as number (\%). NMBAs: neuromuscular blocking agents. 
allergic reaction. The worldwide reported incidence of perioperative anaphylaxis is varies greatly, ranging between $1: 3,500$ and $1: 20,000[1,3,9,10]$. Anaphylaxis may present with mild symptoms such as erythema and urticaria, and can also cause hypotension and tachycardia, as well as severe life-threatening bronchospasm and cardiovascular collapse. When anaphylaxis occurs during general anesthesia, early signs and symptoms are largely unrecognized. Patients cannot report their symptoms owing to their unconscious state, and surgical drapes covering the patient interfere with the identification of initial skin manifestations. In addition, anesthesiologists may consider signs of cardiovascular deterioration such as hypotension or tachycardia as a response caused by general or regional anesthesia, thereby ignoring the severity. As a result, anaphylaxis is generally identified when serious cardiovascular and respiratory compromise have developed, and appropriate treatment is not performed rapidly [11].

Almost all drugs and substances used for anesthesia or surgery in patients during the perioperative period can also cause perioperative anaphylaxis. In general, NMBAs, antibiotics, latex, hypnotics, and antiseptic agents are known to be common causative agents. Depending on the country or region, NMBAs or antibiotics have been reported as a leading cause [1,3]. Identification of causative agents in patients who have experienced an adverse allergic reaction, including anaphylaxis, during anesthesia is essential for the prevention of anaphylaxis during the subsequent delivery of anesthesia. Anesthesiologists should always keep in mind that NMBAs are the most common causative agents of perioperative anaphylaxis.

Anaphylaxis due to NMBAs has the potential to result in mortality even after rapid and appropriate treatment [12]. The ideal method to prevent these outcomes is the performance of allergy skin tests for NMBAs in all patients scheduled for anesthesia to confirm the presence of causative agents. However, because anaphylaxis due to NMBAs is a very rare phenomenon, and evidence is lacking regarding the predictive value of skin tests, the use of systematic preoperative screening skin tests for NMBAs is not recommended $[4,13,14]$. Nevertheless, if risk factors for allergic reactions to NMBAs can be defined, a selective screening test for these risk groups will be important [15].

Recently, studies that focus on the identification of risk factors that can predict positive skin tests for NMBAs have been reported. Tamayo et al. $[5,16]$ reported a study in which skin prick tests (SPTs) for anesthetic drugs were performed in a general population scheduled for anesthesia, and the relationship between age, sex, a history of drug allergy, a history of atopy, a family history of allergy, a history of previous general anesthesia, and SPT was analyzed. Only a prior history of drug allergy was a predictive factor for a positive SPT. Moreover, Hagau et al. [6] reported that preoperative skin tests for NMBAs may be necessary in patients with a history of allergy to nonanesthetic agents. In 2016, Hagau et al. [7] reported skin tests (SPT \& IDT) for NMBAs in patients with a history of allergy to antibiotics and in a control group. The authors found that $46.9 \%$ of patients with antibiotic hypersensitivity had a positive skin test for NMBAs, in comparison to $23.4 \%$ of the control group, and the difference between two groups was significant. When all skin tests performed and skin tests with positive resulst were compared, 65 out of 392 skin tests (16.6\%) in antibiotic allergy group, and 23 out of 288 skin tests (8.0\%) in the control group, showed positive reactions. A significant difference was found between these two groups. Consequently, the authors reported that patients with a history of allergy to antibiotics seem to have a higher incidence of positive skin tests for NMBAs, and the risk of developing intraoperative anaphylaxis may be higher in patients with antibiotic hypersensitivity compared to the general population [7].

In the present study, 26 out of 451 patients (5.8\%) showed positive skin test results, with positive results in only 2 out of 43 patients $(4.7 \%)$ with antibiotic allergy. In addition, 86 skin tests were performed in patients with antibiotic allergy, and only 2 of those $(2.3 \%)$ showed positive findings. In our study, IDTs for rocuronium and cisatracurium only were performed, while Hagau et al. [7] included succinylcholine, atracurium, etc.; thus it is difficult to compare these study results directly. However, the IDT for rocuronium in patients with antibiotic allergy was specifically examined in both studies, and the concentration and the amount of rocuronium and the positive criteria used for the IDT were similar. However, there were no positive results in 43 patients with antibiotic allergy in our study, in constrast to the study of Hagau et al. [7], which found positive results in 24 out of 97 patients (24.7\%). In addition, drug allergy, especially antibiotic allergy, was shown to be a risk factor for a positive skin test of NMBAs in two previous studies $[7,16]$. However, in our study, neither allergy was associated with the skin test for NMBAs (Table 2).

In patients with a positive IDT for either rocuronium or cisatracurium, a muscle relaxant with a negative IDT was used for anesthesia. A skin test for vecuronium was additionally performed in two patients with a positive IDT for both NMBAs. In these patients, the results were negative, and vecuronium was used during anesthesia. Fortunately, there were no allergic reactions in any of the investigated patients.

The limitations of our study include the retrospective nature of study, with the use of medical records, and the fact that the study was conducted only in patients with an allergy history and the IDT was not managed precisely according to the standard. A multicenter and large scale prospective study to identify predictive factors of perioperative anaphylaxis due to NMBAs should be conducted in the future. 
In conclusion, we found no association between allergy history and positive skin tests for NMBAs in this study. Therefore, a systematic screening test for NMBAs prior to anesthesia is not recommended even in patients with an allergy history. It is ad- visable to perform the skin test to identify the causative agent in patients who have experienced a previous adverse allergic reaction to NMBAs or other anesthetic agents.

\section{References}

1. Laxenaire MC, Mertes PM. Anaphylaxis during anaesthesia. Results of a two-year survey in France. Br J Anaesth 2001; 87: 549-58.

2. Jang YH, Kim SG, Son YH, Park JM. Rocuronium bromide induced anaphylaxis in a child -A case report-. Korean J Anesthesiol 2010; 59: 411-5.

3. Gurrieri C, Weingarten TN, Martin DP, Babovic N, Narr BJ, Sprung J, et al. Allergic reactions during anesthesia at a large United States referral center. Anesth Analg 2011; 113: 1202-12.

4. Mertes PM, Malinovsky JM, Jouffroy L, Aberer W, Terreehorst I, Brockow K, et al. Reducing the risk of anaphylaxis during anesthesia: 2011 updated guidelines for clinical practice. J Investig Allergol Clin Immunol 2011; 21: 442-53.

5. Tamayo E, Alvarez FJ, Rodríguez-Ceron G, Gómez-Herreras JI, Castrodeza J. Prevalence of positive prick test to anaesthetic drugs in the surgical population. Allergy 2006; 61: 952-3.

6. Hagau N, Gherman-Ionica N, Hagau D, Tranca S, Sfichi M, Longrois D. Is a positive history of non-anaesthetic drug allergy a predictive factor for positive allergy tests to anaesthetics? Br J Clin Pharmacol 2012; 73: 460-6.

7. Hagau N, Gherman N, Cocis M, Petrisor C. Antibiotic-induced immediate type hypersensitivity is a risk factor for positive allergy skin tests for neuromuscular blocking agents. Allergol Int 2016; 65: 52-5.

8. Ebo DG, Fisher MM, Hagendorens MM, Bridts CH, Stevens WJ. Anaphylaxis during anaesthesia: diagnostic approach. Allergy 2007; 62: 471-87.

9. Fasting S, Gisvold SE. Serious intraoperative problems--a five-year review of 83,844 anesthetics. Can J Anaesth 2002; 49: 545-53.

10. Fisher MM, Baldo BA. The incidence and clinical features of anaphylactic reactions during anesthesia in Australia. Ann Fr Anesth Reanim 1993; 12: 97-104.

11. Pajno GB, Crisafulli G, Caminiti L, Marseglia GL, Cardinale F, Paravati F, et al. Perioperative allergy: therapy. Int J Immunopathol Pharmacol 2011; 24(3 Suppl): S101-4.

12. Reitter M, Petitpain N, Latarche C, Cottin J, Massy N, Demoly P, et al. Fatal anaphylaxis with neuromuscular blocking agents: a risk factor and management analysis. Allergy 2014; 69: 954-9.

13. Porri F, Pradal M, Rud C, Charpin D, Alazia M, Gouin F, et al. Is systematic preoperative screening for muscle relaxant and latex allergy advisable? Allergy 1995; 50: 374-7.

14. Ewan PW, Dugué P, Mirakian R, Dixon TA, Harper JN, Nasser SM. BSACI guidelines for the investigation of suspected anaphylaxis during general anaesthesia. Clin Exp Allergy 2010; 40: 15-31.

15. Mertes PM, Aimone-Gastin I, Guéant-Rodriguez RM, Mouton-Faivre C, Audibert G, O'Brien J, et al. Hypersensitivity reactions to neuromuscular blocking agents. Curr Pharm Des 2008; 14: 2809-25.

16. Tamayo E, Javier Alvarez F, Rodríguez-Ceron G, Gómez-Herreras JI, Fernández A, Castrodeza J. Prevalence of positive prick test to neuromuscular blocking drugs in the surgical population. Br J Clin Pharmacol 2006; 62: 506-7. 